\title{
Concurrent schedules of response duration
}

\author{
GERALD D. LACHTER \\ C. W. Post College, Long Island University, Greenvale, New York
}

Three albino rats were exposed to concurrent schedules in which reinforcement could be obtained if a particular lever-holding duration was met or exceeded. The criterion duration was systematically increased on one lever through values of $1.6,2.4,3.2$, and $4.0 \mathrm{sec}$, while remaining constant at $1.6 \mathrm{sec}$ on the other lever. All animals demonstrated the ability to make temporal discriminations on both levers with a reasonable degree of accuracy. Changes in criterion duration were found to affect primarily the bias term of the logarithmic matching function.

Since Herrnstein's (1961) initial demonstration of matching in concurrent schedules, the matching law has been shown to provide a relatively accurate description of behavior in choice procedures under a wide range of reinforcement conditions.

In a generalization of the matching equation, Baum (1974) noted that a power function provided a better fit to the available data and suggested an equation of the form:

$$
B_{1} / B_{2}=K\left(R_{1} / R_{2}\right)^{a} \text {, }
$$

where $B_{1}$ and $B_{2}$ refer to the rate of responding on the alternatives, $R_{1}$ and $R_{2}$ refer to the comparable rates of reinforcement, and $\mathrm{K}$ and a are parameters that denote bias and sensitivity, respectively. When plotted in logarithmic form as

$$
\log \left(\mathrm{B}_{1} / \mathrm{B}_{2}\right)=\mathrm{a} \log \left(\mathrm{R}_{1} / \mathrm{R}_{2}\right)+\log \mathrm{K},
$$

sensitivity (a) is shown by the slope and bias (K) by the $y$-intercept of the best-fitting regression line.

This general formulation has had great success in dealing with a wide range of reinforcement manipulations, including schedule parameters (Catania, 1966; DeVilliers, 1977), quality (Hollard \& Davison, 1971), immediacy (Chung \& Herrnstein, 1967), and magnitude (Brownstein, 1971; DeVilliers \& Millenson, 1972). Similarly, some investigations have employed different responses, or response properties. For example, Baunit and Rachlin (1969) measured the time spent standing on one side or the other of an experimental chamber and found a close fit to the logarithmic matching function.

Moffitt and Shimp (1971), Shimp (1968), and Staddon (1968), have demonstrated that choice between two concurrent interresponse times produces similar functions relating response and reinforcement ratios to those found previously with leverpress and keypeck responses.

The author's mailing address is: Department of Psychology, C. W. Post Campus, Long Island University, Greenvale, NY 11548.
More recently, Hunter and Davison (1982) demonstrated that the matching function can account for data in which response force is manipulated within a concurrent schedule. An additional parameter was added to the basic equation, but this is similar to those that have been added to deal with immediacy and amount of reinforcement (see, for example, Baum \& Rachlin, 1969, and Hollard \& Davison, 1971).

The present investigation was designed to extend the matching function to direct measures of response duration, when the criterion required for reinforcement was systematically manipulated.

\section{METHOD}

\section{Subjects}

Three experimentally naive laboratory-bred male SpragueDawley albino rats were maintained and trained at $80 \%( \pm 10 \mathrm{gm})$ of their free-feeding weights. The subjects were approximately 160 days old $(500-525 \mathrm{gm})$ at the start of the experiment.

\section{Apparatus}

An operant conditioning chamber, with Plexiglas sides, aluminum front and rear walls, and measuring $22 \mathrm{~cm}$ long $\mathrm{x}$ $25 \mathrm{~cm}$ wide $\times 25 \mathrm{~cm}$ high, was enclosed in a Gerbrands Model 1101 research chest. Two standard response levers, each requiring a force of $0.30 \mathrm{~N}$ for activation, were mounted on the front wall $2 \mathrm{~cm}$ above the grid floor and $4 \mathrm{~cm}$ to the left and right, respectively, of a $5-\mathrm{cm}$ circular opening into which $45-\mathrm{mg}$ Noyes food pellets could be delivered. The separation between the levers did not permit them to be depressed simultaneously. A 28-V houselight mounted behind the front wall provided diffuse overall chamber illumination. Extraneous sounds were masked by a ventilating fan and $80 \mathrm{~dB}$ of continuously present white noise. Experimental contingencies and recording were controlled by BRS-Foringer solid-state circuitry.

\section{Procedure}

The subjects were initially shaped to hold the left and right levers for $0.10 \mathrm{sec}$ by the method of successive approximations. Following this initial shaping, the right lever was removed from the chamber and the criterion duration was gradually increased on the left lever until a value of $1.6 \mathrm{sec}$ had been reached. The right lever was reinserted, the left lever was removed, and the same procedure was repeated. Shaping to the $1.6-\mathrm{sec}$ criterion on both levers was completed in 12 sessions, following which both levers were continuously available throughout the course of the experiment. All subjects were then exposed to a concurrent schedule consisting of two independent 16 -sec variable- 
interval (VI) schedules. A lever-holding criterion of $1.6 \mathrm{sec}$ was in effect for both levers. Reinforcement was delivered, following its availability by the VI schedules, for a lever release following a holding value equal to or greater than the criterion. This initial condition remained in effect for 45 sessions. Following the 1.6-sec/1.6-sec value, the criterion holding duration was manipulated on the preferred lever through values of $2.4 \mathrm{sec}$ (45 sessions), $3.2 \mathrm{sec}$ ( 30 sessions), $4.0 \mathrm{sec}$ ( 30 sessions), and a return to the original $1.6-\mathrm{sec} / 1.6-\mathrm{sec}$ value (50 sessions). All sessions were of 30 -min duration.

\section{RESULTS}

The primary measure of interest, response duration, was collected by the use of a 20-bin shift register with a bin width of $0.50 \mathrm{sec}$. The distributions of response duration are an indication of the accuracy of performance on the two levers. As can be seen in Figure 1, performance on the lever with the 1.6-sec criterion was relatively stable across all experimental manipulations. The distributions are unimodal, with a peak at either 2.0 or $2.5 \mathrm{sec}$. The accuracy with which these responses were made was not affected by the criterion value in force on the other lever. The distributions obtained for the changing criterion values are somewhat different.
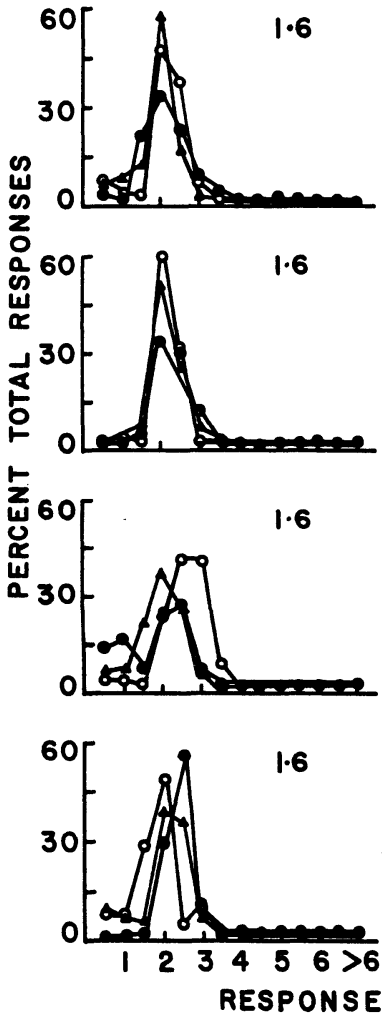

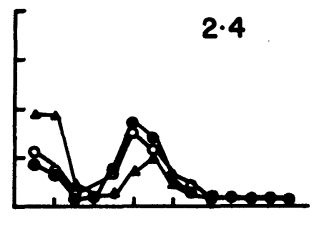

$3 \cdot 2$
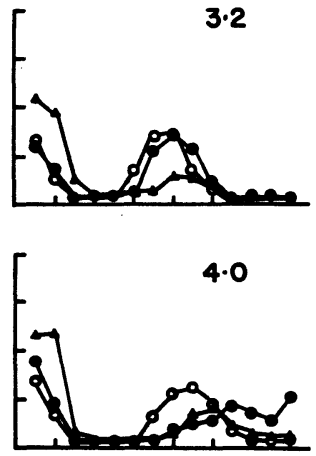

1.6

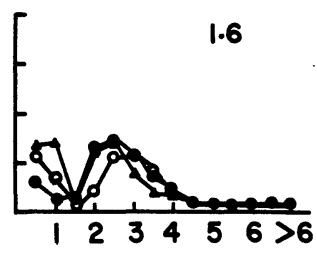

DURATION (SEC)
Figure 1. Percentage of total response as a function of response duration. Filled circles indicate Subject 1, open circles Subject 2, and triangles Subject 3. The numbers in each panel indicate the criterion duration in effect. Each point is the mean of the last six sessions of exposure at each criterion value.
These functions are bimodal, with one peak at very short durations $(0.5$ or $1.0 \mathrm{sec})$ and a second peak at or beyond the criterion value. Response accuracy was generally good, with the second peak moving in the appropriate direction as the criterion duration was increased. However, the changing criterion distributions are more variable than their constant criterion counterparts.

Following Hunter and Davison (1982), criterion value was treated as producing absolute rather than relative effects on holding duration. For this reason, the criterion ratio $\left(C_{1} / C_{2}\right)$ is not raised to a power but multiplies the reinforcement ratio $\left(R_{1} / R_{2}\right)$. The general form of this relationship would be expressed as:

$$
\log \left(\mathrm{T}_{1} / \mathrm{T}_{2}\right)=\mathrm{a} \log \left(\mathrm{R}_{1} / \mathrm{R}_{2}\right)+\log \left(\mathrm{C}_{1} / \mathrm{C}_{2}\right)+\log \mathrm{K}
$$

Figure 2 demonstrates that the addition of the criterion value to the usual matching equation produces functions that are similar to those previously obtained with concurrent schedules. Subjects 2 and 3 show undermatching, whereas Subject 1 shows overmatching. However, averaged across all subjects, the exponent is very close to 1.0. Additionally, all subjects maintained a bias for one lever as shown by the value of the y-intercept. This bias was maintained across all the values of criterion duration employed.

\section{DISCUSSION}

The duration distribution data clearly indicate that animals are capable of making relatively accurate temporal discriminations in a concurrent situation. The distributions indicate that changes in the criterion duration resulted in peak responding shifting in the direction of the new criterion value. However, as the criterion duration was increased, there was a general decrease in response accuracy. This finding is similar to that obtained in previous investigations employing response duration measures (cf. Lachter \& Corey, 1982).

Changes in criterion duration did not produce systematic changes in the response distributions on the constant criterion lever, indicating an absolute effect upon responding of this manipulation. The presence of an interaction of the form usually referred to as matching provides further information about the effect of criterion duration. Since changes in criterion value primarily affected the intercept rather than the slope of the functions, it is clear that a strong response bias was maintained. However, changes in the response duration ratios were also affected by the reinforcement ratios. The deviation between the response duration ratios and the reinforcement ratios tended to increase as the criterion duration was increased. This is a natural consequence of the particular manipulation employed. Although the criterion duration was systematically increased on one lever, all subjects were still able to obtain a substantial number of reinforcers on that lever. Since accuracy decreased with increases in criterion duration, more time, on the average, was required for a reinforcer to be obtained. This time period, unlike the interreinforcement time specified by the VI schedules, was not affected by the time spent responding on the other lever. In order for reinforcement to occur, a criterion duration response was necessary after availability had been provided by the VI schedule. Since accuracy was reduced at higher criterion values, an increased amount of time was necessarily spent on 

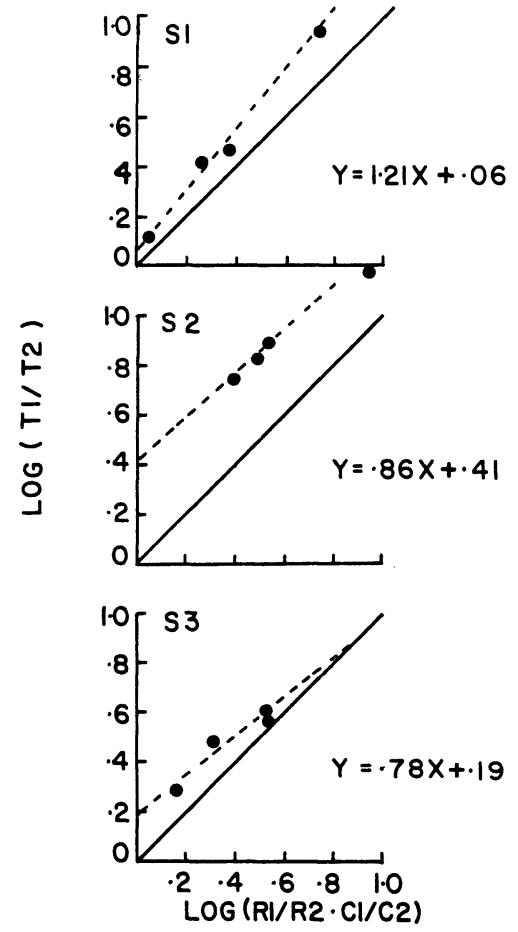

Figure 2. The logarithm of the ratio of holding time (T) as a function of the logarithm of the reinforcement ratio (R) multiplied by the criterion ratio (C). The solid line indicates perfect matching. The dashed line was obtained by the method of least squares. Each point is the mean of the last three sessions of exposure to a given criterion.

this lever. The differential amounts of time required were a consequence of changes in criterion value, and these differentials could not be substantially altered by the organism.

Conceptually, the organism was emitting criterion responses on a variable-ratio schedule whose value increased as the criterion duration was increased. Thus, the biased matching obtained with response duration measures is not unlike that obtained with ratio schedules (cf. Bacotti, 1977).

That holding times were affected by absolute rather than relative criterion values brings the study of response duration into contact with the data dealing with response force. Hunter and Davison (1982) demonstrated that the force requirement in effect for a response exerts an absolute rather than a relative effect on responding, and required the addition of a term to the matching equation to account for this effect. The similar findings for response duration suggest that two mechanisms may operate to produce matching. Reinforcement exerts a relative effect on response frequency (or rate), whereas variations in the value of force or duration required exert absolute effects.
The results of the present investigation therefore extend the generality of the matching function to measures of response duration and further demonstrate its strength in accurately describing behavior.

\section{REFERENCES}

BacotTi, A. V. (1977). Matching under concurrent fixed-ratio variable-interval schedules of food presentation. Journal of the Experimental Analysis of Behavior, 25, 171-182.

BaUm, W. M. (1974). On two types of deviation from the matching law: Bias and undermatching. Journal of the Experimental Analysis of Behavior, 22, 231-242.

BAUM, W. M., \& RACHLin, H. C. (1969). Choice as time allocation. Journal of the Experimental Analysis of Behavior, 12, 861-874.

Brownstein, A. J. (1971). Concurrent schedules of responseindependent reinforcement: Duration of a reinforcing stimulus. Journal of the Experimental Analysis of Behavior, 15, 211-214.

Catania, A. C. (1966). Concurrent operants. In W. K. Honig (Ed.), Operant behavior: Areas of research and application (pp. 213-270). New York: Appleton-Century-Crofts.

Chung, S. H., ( Herrnstein, R. J. (1967). Choice and delay of reinforcement. Journal of the Experimental Analysis of Behavior, 10, 67-74.

DeVilliers, P. A. (1977). Choice in concurrent schedules and a quantitative formulation of the law of effect. In W. K. Honig \& J. E. R. Staddon (Eds.), Handbook of operant behavior (pp. 233-287). Englewood Cliffs, NJ: Prentice Hall.

DeVilliers, P. A., \& Millenson, J. R. (1972). Concurrent performances: A baseline for the study of conditioned anxiety. Journal of the Experimental Analysis of Behavior, 18, 287-294.

HerRnste in, R. J. (1961). Relative and absolute strength of response as a function of frequency of reinforcement. Journal of the Experimental Analysis of Behavior, 4, 267-272.

Hollard, V., \& Davison, M. C. (1971). Preference for qualitatively different reinforcers. Journal of the Experimental Analysis of Behavior, 16, 375-380.

Hunter, I., \& DAvison, M. C. (1982). Independence of response force and reinforcement rate on concurrent variable-interval schedule performance. Journal of the Experimental Analysis of Behavior, 37, 183-198.

LAChter, G. D., \& CoREy, J. R. (1982). Variability of the duration of an operant. Behavior Analysis Letters, 2, 97-102.

Moffitt, M., \& Shimp, C, P. (1971). Two-key concurrent paced variable-interval schedules of reinforcement. Journal of the Experimental Analysis of Behavior, 16, 39-49.

Shimp, C. P. (1968). Magnitude and frequency of reinforcement and frequency of interresponse times. Journal of the Experimental Analysis of Behavior, 11, 525-535.

Staddon, J. E. R. (1968). Spaced responding and choice: A preliminary analysis. Journal of the Experimental Analysis of Behavior, 11, 669-682.

(Manuscript received for publication February 27, 1984.) 